\title{
Fanconi syndrome after Ifosfamide exposure - case report
}

\author{
Sónia M. Gomes ${ }^{1}$, Ana M. Garcia ${ }^{1}$, Telma Francisco ${ }^{1}$, Gilda Teixeira ${ }^{2}$, Maria J. Ribeiro ${ }^{3}$, Ana P. Serrão ${ }^{1}$ \\ 1 Pediatric Nephrology Unit, Pediatrics Department, Hospital de Dona Estefânia, Centro Hospital Universitário de Lisboa Central, EPE, Lisboa, Portugal. \\ ${ }^{2}$ Hematopoietic Cell Transplantation Unit, Haematology Department, Instituto Português de Oncologia Francisco Gentil, Lisboa, Portugal. \\ ${ }^{3}$ Pediatric Unit, Children and Adolescents Oncology Department, Instituto Português de Oncologia Francisco Gentil, Lisboa, Portugal.
}

\section{ABSTRACT}

Ifosfamide is an antineoplastic drug widely used in the treatment of paediatric malignancies. However, in up to $50 \%$ of patients, it is associated with nephrotoxicity ranging from asymptomatic tubulopathy to overt renal failure.

A two-year-old Caucasian boy was diagnosed with stage IV Burkitt lymphoma, with hepatic and renal and bone marrow involvement. Baseline evaluation showed GFR of $60 \mathrm{~mL} / \mathrm{min} / 1.73 \mathrm{~m}^{2}$. He started chemotherapy with LMB 96 protocol group B with 5 courses of chemotherapy with vincristine, cyclophosphamide, doxorubicin, prednisone, and intrathecal administration of cytarabine and methotrexate. After the first chemo protocol, the patient was in remission and recovered normal renal function, but three months later he relapsed with involvement of the liver and kidneys. The patient initiated a salvage regimen with R-ICE (rituximab - ifosfamide, carboplatin, etoposide) intrathecal methotrexate and cytarabine and allogeneic stem cell transplantation was proposed. After achieving complete remission, he underwent allogeneic stem cell transplantation with busulfan and cyclophosphamide. Graft versus host disease prophylaxis was made with tacrolimus and methotrexate and infection prophylaxis with fluconazole and acyclovir.

However, during treatment of the relapse, the patient presented downward crossing of weight and height centiles without recovery after treatment terminus and, following transplantation, consecutive laboratory testing suggested tubulopathy. Upon nephrologist referral, he was diagnosed with Fanconi syndrome and adequate supplementation was initiated with improvement of the patient's general condition and slow centile catch up. After literature review, the most probable causing agent was determined to be ifosfamide, as the nephrotoxic effects of the other medications prescribed tend to be reversible after stopping.

Nephrotoxicity secondary to chemotherapy is a major cause of morbidity in paediatric cancer survivors. Our case represents a rare situation with unspecific clinical signs. Clinicians must be alert to the necessity of close monitoring to identify renal toxicity, mainly tubular dysfunction, as early as possible and allow adequate supplementation, which is crucial in preventing side effects.

Keywords: Ifosfamide, Nephrotoxicity, Fanconi Syndrome.

\section{INTRODUCTION}

Ifosfamide is an isomer of cyclophosphamide with considerable efficacy against a wide range of hematological and non-hematological neoplasms in children. However, it is associated with nephrotoxicity in up to $50 \%$ of patients, depending on the screening method. ${ }^{1,2}$ Ifosfamide nephrotoxicity may manifest abruptly or subclinically and belatedly several months or years after exposure, with different degrees of severity, ranging from asymptomatic tubulopathy to overt renal failure ${ }^{1-3}$ Important metabolic consequences include acidosis and electrolyte disorders, with the need for complex supplementation therapy, decreased quality of life, and also limitations on optimal antineoplastic treatment of relapses. ${ }^{4}$

Fanconi syndrome is a proximal tubulopathy characterized by proximal tubular loss of glucose, phosphate, bicarbonate, amino acid and proteins which may result in rickets and growth impairment. ${ }^{5}$ It has been described as a late effect of Ifosfamide in only 5 to $7 \%$ of patients treated. ${ }^{2,6}$
In this case report the authors describe a case of Fanconi syndrome diagnosed 17 months after exposure to ifosfamide for Burkitt lymphoma treatment.

\section{CASE REPORT}

A 33-month-old boy, with unremarkable personal and family history, presented with dyspnea and abdominal distension with a palpable mass on the lower left abdominal quadrant. Thoracic, abdominal, and pelvic computed tomography was performed, showing: "large abdominal adenopatic conglomerate, retroperitoneal and mediastinal adenopathies, coexisting numerous cervical adenopathies (...) signs of probable splenic and renal involvement; ascites and bilateral pleural effusion." The bone marrow examination revealed $6.4 \%$ of lymphoid cells with morphology compatible with Burkitt lymphoma. Lumbar puncture showed no central nervous system involvement. The patient was diagnosed with stage IV Burkitt lymphoma with hepatic, renal and 
bone marrow involvement. Initial laboratory evaluation showed a creatinine of $0.71 \mathrm{mg} / \mathrm{dL}$, corresponding to an estimated GFR (eGFR) of $51 \mathrm{~mL} / \mathrm{min} / 1.73 \mathrm{~m}^{2}$, calculated with the Revised Schwartz formula
(eGFR $=[$ Height $(\mathrm{cm}) \times 0.413] /$ creatinine $(\mathrm{mg} / \mathrm{dL}))$ and normal urinalysis (Table 1). He received chemotherapy with LMB 96 protocol group $B$ (according to the percentage of blasts in bone marrow) consisting of

\section{Table I}

Laboratory findings during disease course.

\begin{tabular}{|c|c|c|c|c|c|c|c|c|}
\hline \multirow[t]{2}{*}{ Age } & $\begin{array}{l}\text { At diagnosis of } \\
\text { Burkitt } \\
\text { Iymphoma }\end{array}$ & $\begin{array}{c}\text { After } 1^{\text {st }} \\
\text { treatment } \\
\text { (LMB } 96 \\
\text { protocol group } \\
\text { B - Fig. 1) }\end{array}$ & Relapse & $\begin{array}{l}\text { After } 2^{\text {nd }} \\
\text { treatment and } \\
\text { before blood } \\
\text { marrow } \\
\text { transplant }\end{array}$ & $\begin{array}{l}\text { After blood } \\
\text { marrow } \\
\text { transplant } \\
\text { (R-ICE protocol } \\
\text { - Fig. 2) } \\
\end{array}$ & $\begin{array}{c}\text { After } \\
\text { tacrolimus } \\
\text { suspension }\end{array}$ & $\begin{array}{l}\text { At diagnosis of } \\
\text { Fanconi } \\
\text { syndrome } \\
\text { (nephrology } \\
\text { appointment) }\end{array}$ & \multirow[t]{2}{*}{ Reference range } \\
\hline & $\begin{array}{l}2 \mathrm{yr} 9 \mathrm{mo} \\
(33 \mathrm{mo}) \\
\end{array}$ & $\begin{array}{c}2 \mathrm{yr} 11 \mathrm{mo} \\
(35 \mathrm{mo})\end{array}$ & $\begin{array}{l}3 y r 3 \mathrm{mo} \\
(39 \mathrm{mo})\end{array}$ & $\begin{array}{l}3 y r 7 \mathrm{mo} \\
(43 \mathrm{mo})\end{array}$ & $\begin{array}{l}3 \mathrm{yr} 8 \mathrm{mo} \\
(44 \mathrm{mo})\end{array}$ & $\begin{array}{c}4 y r 11 \mathrm{mo} \\
(59 \mathrm{mo})\end{array}$ & $\begin{array}{r}5 y r 4 \mathrm{mo} \\
(64 \mathrm{mo}) \\
\end{array}$ & \\
\hline \multicolumn{9}{|c|}{ Peripheral blood } \\
\hline WBC (/uL) & 8440 & 1680 & 7030 & 5230 & 6670 & 10400 & 7340 & $5000-15000$ \\
\hline Neutrophils (/uL) & 4740 & 360 & 342 & 3870 & 6430 & 6540 & 3750 & $1500-8000$ \\
\hline Hemoglobin (g/dL) & 10.2 & 10.0 & 13.5 & 12.7 & 10.4 & 12.7 & 11.2 & $11.5-13.5$ \\
\hline Platelets (/uL) & 388000 & 1020000 & 362000 & 346000 & 256000 & 247000 & 332000 & $200000-450000$ \\
\hline Glucose (mg/dL) & 50 & 50 & & 58 & 114 & 94 & 87 & $60-99$ \\
\hline Urea $(\mathrm{mg} / \mathrm{dL})$ & 24 & 24 & & 26 & 11 & 39 & 35 & $15-36$ \\
\hline Creatinine (mg/dL) & 0.71 & 0.37 & 0.43 & 0.42 & 0.39 & 0.63 & 0.69 & $0.44-0.69$ \\
\hline Uric acid (mg/dL) & 3.8 & 3.7 & 5.2 & 2.6 & $<1$ & 1.0 & 1.5 & $1.8-4.9$ \\
\hline Sodium (mEq/L) & 136 & 137 & 137 & 140 & 140 & 137 & 136 & $136-145$ \\
\hline Potassium (mEq/L) & 3.4 & 4.1 & 4.5 & 4.1 & 3.6 & 3.7 & 2.8 & $3.4-4.7$ \\
\hline Chloride (mEq/L) & 104 & 104 & 105 & 106 & 109 & 111 & 108 & $98-107$ \\
\hline Phosphate (mg/dL) & 5.7 & 5.7 & & 4.9 & 2.7 & 2.1 & 1.8 & $4.1-5.9$ \\
\hline Magnesium (mg/dL) & 1.8 & 1.8 & & 2.3 & 1.8 & 2,2 & 2.3 & $1.7-2.3$ \\
\hline Calcium (mg/dL) & 8 & 10 & & 9.8 & 9.4 & 9.1 & 9.9 & $8.8-10.8$ \\
\hline $\mathrm{GFR}^{*}\left(\mathrm{~mL} / \mathrm{min} / 1.73 \mathrm{~m}^{2}\right)$ & 51 & 105 & 90 & 98 & 106 & 68 & 51 & $>89$ \\
\hline Vitamin D $1.25(\mathrm{pg} / \mathrm{mL})$ & & & & & & & 13.60 & $19.6-54.3$ \\
\hline Vitamin D25 (ng/mL) & & & & & & & 17.7 & $30-100$ \\
\hline $\begin{array}{l}\text { Intact parathyroid } \\
\text { hormone }(\mathrm{pg} / \mathrm{mL})\end{array}$ & & & & & & & 11.70 & $16.23-63.02$ \\
\hline Aldosterone (ng/dL) & & & & & & & 61.8 & $4-44$ \\
\hline Active rennin (uUl/mL) & & & & & & & 220.5 & $15.8-100.8$ \\
\hline \multicolumn{9}{|c|}{ Acid base balance (capillary) } \\
\hline $\mathrm{pH}$ & & & & & & & 7.31 & $7.35-7.45$ \\
\hline pCO2 (mmHg) & & & & & & & 33.3 & $35-45$ \\
\hline HCO3- (mmHg) & & & & & & & 16.6 & $22-26$ \\
\hline $\mathrm{BE}(\mathrm{mEq} / \mathrm{L})$ & & & & & & & -9.7 & $-2.0-2.0$ \\
\hline An Gap (mEq/L) & & & & & & & 13 & $8-16$ \\
\hline \multicolumn{9}{|c|}{ Urinalysis } \\
\hline $\mathrm{pH}$ & 5 & & & 5 & 8 & 7 & 7 & $5-8$ \\
\hline Specific gravity & 1013 & & & 1013 & 1010 & 1009 & & \\
\hline Glucose & negative & & & Negative & 50 & 1000 & $>1000 \mathrm{mg} / \mathrm{dL}$ & \\
\hline Proteins & negative & & & negative & negative & 30 & $50 \mathrm{mg} / \mathrm{dL}$ & \\
\hline $\begin{array}{l}\text { Tubular phosphate } \\
\text { reabsorption (\%) }\end{array}$ & & & & & & & 53 & $>85$ \\
\hline $\begin{array}{l}\text { Fractional excretion of } \\
\text { potassium (\%) }\end{array}$ & & & & & & & 44.7 & $10-30 \%$ \\
\hline $\begin{array}{l}\text { Fractional excretion of uric } \\
\text { acid (\%) }\end{array}$ & & & & & & & 61.1 & $16 \%$ \\
\hline $\begin{array}{l}\text { Abumin:creatinine ratio } \\
(\mathrm{mg} / \mathrm{g})\end{array}$ & & & & & & & 470 & $<30$ \\
\hline
\end{tabular}

* Calculated with the Revised Schwartz Equation for Glomerular Filtration Rate (GFR): GFR = [Height $(\mathrm{cm}) \times 0.413] /$ creatinine $(\mathrm{mg} / \mathrm{dL})$ Legend: $\mathrm{yr}$ - years; mo - months; GFR - Glomerular filtration rate 
Figure 1

LMB 96 protocol group $B$
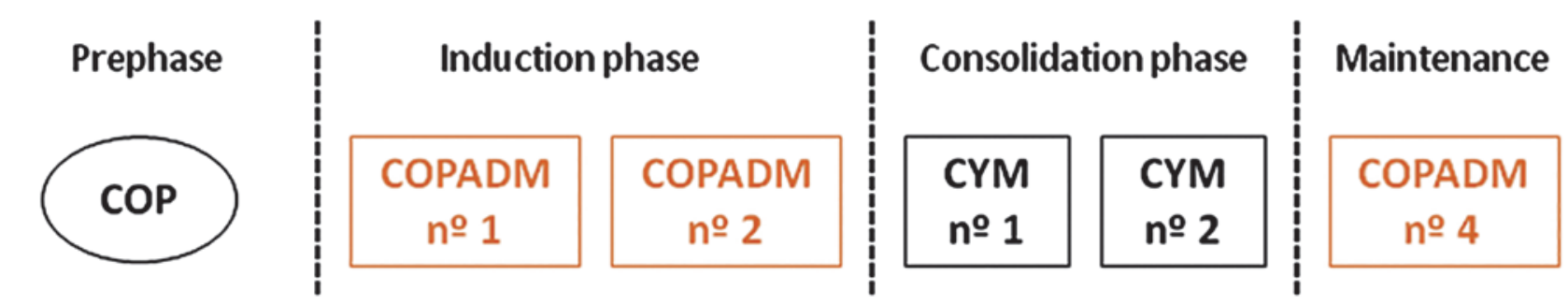

\begin{tabular}{|c|}
\hline $\begin{array}{l}\text { Cyclophosphamide } \\
\text { (300 mg/m², day } 1 \text { ) }\end{array}$ \\
\hline $\begin{array}{l}\text { Oncovin (vincristine; } \\
1 \mathrm{mg} / \mathrm{m}^{2} \text { day } 1 \text { ) }\end{array}$ \\
\hline $\begin{array}{l}\text { Prednisone (60 } \\
\mathrm{mg} / \mathrm{m}^{2} / \mathrm{d} \text {, days } 1-7 \text { ) }\end{array}$ \\
\hline $\begin{array}{l}\text { (+ intrathecal } \\
\text { methotrexate/hydro } \\
\text { cortisone, day 1) }\end{array}$ \\
\hline
\end{tabular}

Cyclophosphamide $\left(1.5 \mathrm{~g} / \mathrm{m}^{2}\right.$ in
COPADM $1,3 \mathrm{~g} / \mathrm{m} 2$ in COPADM 2$)$
Oncovin ( $2 \mathrm{mg} / \mathrm{m}^{2}$, day 1$)$
Prednisone $\left(60 \mathrm{mg} / \mathrm{m}^{2} / \mathrm{d}\right.$, days $\left.1-7\right)$
Adriamycin (doxorubicin; 60
$\mathrm{mg} / \mathrm{m}^{2}$, day 2 )
Methotrexate ( $3 \mathrm{~g} / \mathrm{m}^{2}$ in $3-\mathrm{h}$
infusion, day 1 ) plus leucovorin
rescue
(+ intrathecal methotrexate/
hydrocortisone, day 2 and day 6 )

Cytarabine $\left(100 \mathrm{mg} / \mathrm{m}^{2}\right.$ in continuous infusion, days 26)

Methotrexate $\left(3 \mathrm{~g} / \mathrm{m}^{2}\right.$ in $3-\mathrm{h}$ infusion, day 1) plus leucovorin rescue

(+ intrathecal methotrexated hydrocortisone, day 1 (+ intrathecal cytarabine) hydrocortisone day 6 ) one course with cyclophosphamide, vincristine and prednisone; 2 courses with vincristine, cyclophosphamide, doxorubicin, prednisone and high-dose intrathecal methotrexate ( $3 \mathrm{~g} / \mathrm{m}^{2}$ over 3 hours); and 2 courses of intrathecal methotrexate and continuous infusion cytarabine (Figure 1). Subsequently, he achieved remission and there was improvement of renal function with normalization of eGFR.

Three months later, the disease relapsed again with hepatic renal and bone marrow involvement. The thoracic, abdominal, and pelvic computed tomography showed: "lower mediastinal adenopathic conglomerate with about $60 \mathrm{~mm}$; a voluminous lesion with a soft tissue component in the right chest wall $(70 \times 82 \mathrm{~mm})$, with an under and extrathoracic component, extending along the costophrenic sinus to the homolateral diaphragm pillar with extensive pre-foraminal paravertebral component and pleural infiltration; there are aspects compatible with renal relapse translated by the presence of several cortical nodular structures, (...)". The patient, then aged 3 years and 2 months old, was started on a salvage course of chemotherapy with ifosfamide, carboplatin, etoposide and rituximab (R-ICE), intrathecal administration of methotrexate and cytarabine (Figure 2), and allogeneic stem cell transplantation was proposed. Baseline analyses revealed an eGFR of $88 \mathrm{~mL} / \mathrm{min} / 1.73 \mathrm{~m}^{2}$ and normal urinalysis. A total cumulative dose of $45 \mathrm{~g} / \mathrm{m}^{2}$ of Ifosfamide was administered and adequate hyperhydration and Mesna were used. He achieved remission after five cycles of R-ICE (five months later).
At the age of 3 years and 7 months, the patient underwent allogeneic stem cell transplantation with busulfan and cyclophosphamide. Graft versus host disease prophylaxis was made with tacrolimus and methotrexate and fluconazole and acyclovir were administered for infection prophylaxis. Serum creatinine before transplant was 0.42 $\mathrm{mg} / \mathrm{dL}$, corresponding to an eGFR of $88 \mathrm{~mL} / \mathrm{min} / 1.73 \mathrm{~m} 2$, and urinalysis was normal. No transplant related complications were registered.

During the relapse treatment, the patient presented downward crossing of weight and height centiles without recovery after treatment terminus (Figures 3 and 4). Following transplantation, consecutive laboratory workup showed low plasma levels of uric acid and

\section{Figure 2}

R-ICE treatment protocol.

\begin{tabular}{l|c|c|c|c|c|c}
\multicolumn{1}{l||}{} & \multicolumn{7}{c}{ Day } \\
\hline & 1 & 2 & 3 & 4 & 7 & 14 \\
\hline Rituximab $375 \mathrm{mg} / \mathrm{m}^{2}$ & + & & & & + & + \\
Ifosfamide $2 \mathrm{~g} / \mathrm{m}^{2}$ & & + & + & + & & \\
+ mesna & & + & + & + & & \\
Etoposide $75 \mathrm{mg} / \mathrm{m}^{2}$ & & + & + & + & & \\
Carboplatine AUC 5 (maximum $350 \mathrm{mg} / \mathrm{m}^{2}$ ) & & + & + & + & &
\end{tabular}


Figure 3

Weight growth chart.

WHO child growth standards (birth to 60 months), WHO reference 2007 ( 61 months to 19 years)

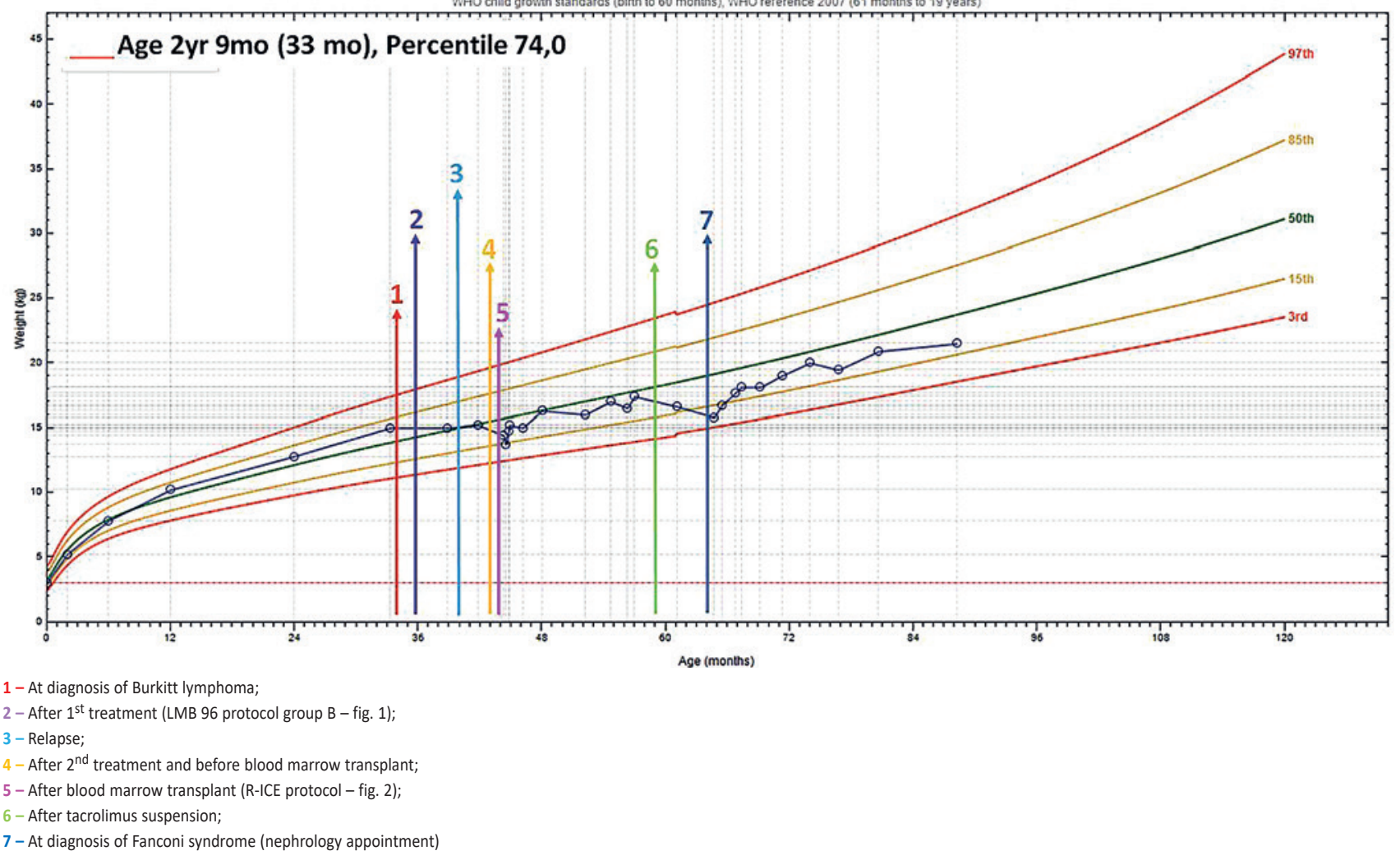

phosphate, glycosuria and proteinuria. Remarkably, these abnormalities didn't resolve after discontinuation of immunosuppressive therapy, which occurred 1 year and 7 months later, when the patient was 5 years old.

At the age of 5 years and 4 months, upon suspicion of renal tubulopathy, the patient was referred to the nephrology unit for further evaluation. He was $16 \mathrm{Kg}$ ( $6^{\text {th }}$ centile) and $102.5 \mathrm{~cm}$ ( $2^{\text {nd }}$ centile), with normal blood pressure ( $50^{\text {th }}-90^{\text {th }}$ centiles). He complained of asthenia, but physical examination was otherwise unremarkable. Laboratory investigation showed an eGFR of $62 \mathrm{~mL} / \mathrm{min} / 1.73 \mathrm{~m}^{2}$, non-anion gap metabolic acidosis, hypophosphatemia with low tubular reabsorption of phosphorus, hypokalaemia with high fractional excretion of potassium, normal magnesium, low plasma levels of uric acid with high fractional excretion of uric acid, proteinuria and glycosuria on urinalysis and albuminuria (Table 1). Ophthalmological evaluation revealed no cystine deposits.

Therefore the patient was diagnosed with Fanconi syndrome secondary to Ifosfamide treatment. He started treatment with potassium and aliskiren (to help reduce the need for potassium supplementation), bicarbonate and phosphate supplements; indomethacin was also prescribed, to reduce renal tubular losses. Later he needed bicarbonate and 1,25-dihydroxycholecalciferol supplementation, due to low 25 and 1,25 vitamin D. After adequate supplementation the patient's general condition and appetite improved with slow centile recovery (Figures 3 and 4).

Currently, the patient is 7 years and 7 months old and he is under regular follow up. It was possible to stop indomethacin, phosphate and 1,25-dihydroxycholecalciferol supplementation, but the patient maintains some features of Fanconi syndrome (acidosis, hypokalemia, glycosuria and proteinuria).

\section{DISCUSSION}

Fanconi syndrome is a proximal tubule defect consisting of a generalized loss of reabsorption capacity, resulting in wasting of glucose, sodium, potassium, bicarbonate, phosphate, amino acids and proteins, in different degrees of severity ${ }^{5}$. It can lead to rickets and growth impairment and has been described as occurring in 5 to $7 \%$ of paediatric patients treated with ifosfamide. ${ }^{2,6}$

Our patient presented with metabolic acidosis, hypophosphatemia, hypokalemia, hypouricemia, proteinuria and glycosuria. Further testing showed low tubular reabsorption of phosphorus and high fractional excretion of potassium and uric acid, thus confirming the diagnosis of Fanconi syndrome. Some features of Fanconi syndrome (hyperchloremia - possibly indicating non-anion gap acidosis - glycosuria, 


\section{Figure 4}

Height growth chart.

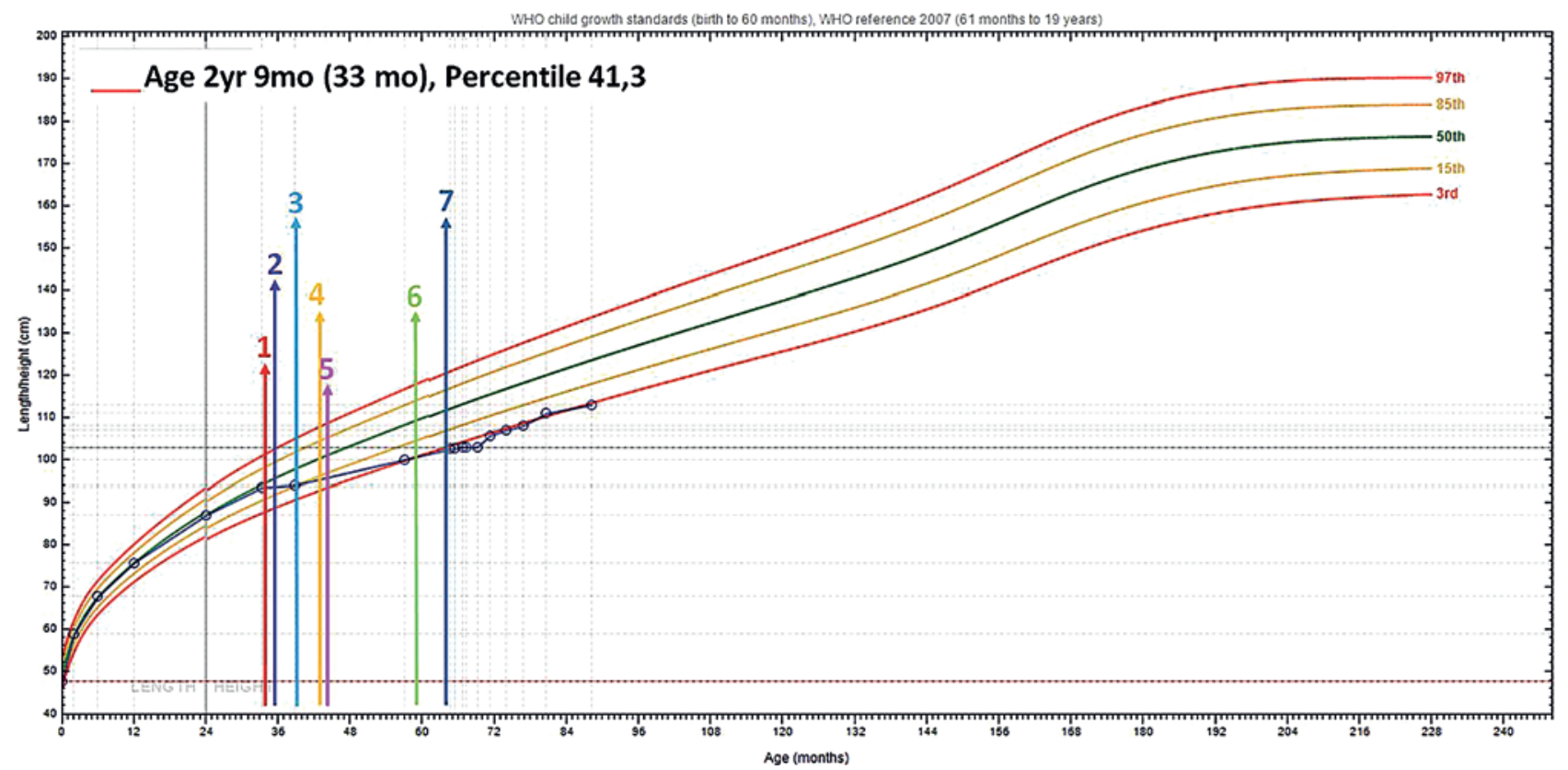

1 - At diagnosis of Burkitt lymphoma;

2 - After $1^{\text {st }}$ treatment (LMB 96 protocol group B - fig. 1);

3 - Relapse;

4 - After $2^{\text {nd }}$ treatment and before blood marrow transplant;

5 - After blood marrow transplant (R-ICE protocol - fig. 2);

6 - After tacrolimus suspension;

7 - At diagnosis of Fanconi syndrome (nephrology appointment)

hypophosphatemia and hypouricemia) appeared after blood marrow transplant, and, so, after treatment with ifosfamide and carboplatin (Table I and Figure 1), but the full picture was only evident at the first nephrology appointment.

It is difficult to assume a direct causative relation for renal damage in patients with complex clinical situations and exposure to different nephrotoxic agents. In our patient, we assumed the Fanconi syndrome to be secondary to chemotherapy because no other causes of renal damage were apparent.

Although cystinosis is the most frequent aetiology of Fanconi Syndrome in children, corneal cystine crystal are present in all patients after the age of 1 year old and Fanconi syndrome is present in virtually all patients at the age of 6 months. ${ }^{7}$ Our patient, not only had a normal ophthalmological exam without complaints of photophobia, but also Fanconi syndrome was not present at the time of Burkitt lymphoma diagnosis (33 months old) leading us to believe that cystinosis in not the cause for his renal dysfunction.

Of note, the patient presented with renal involvement with decreased GFR at the time of Burkitt lymphoma diagnosis. However, after achieving remission, renal function normalized and severe deterioration was apparent only after the second chemotherapy protocol.
Amongst the chemotherapy agents used, ifosfamide, carboplatin, methotrexate and tacrolimus have all been implicated in tubular nephrotoxicity.

Ifosfamide is an alkylating synthetic analog of cyclophosphamide and both can cause hemorrhagic cystitis. The use of Mesna has reduced the occurrence of hemorrhagic cystitis. ${ }^{8}$

Ifosfamide is transformed to its active metabolites mainly by cytochrome P450 and is excreted in urine predominantly as acrolein and inactive metabolites; $20 \%$ of the administered dose is excreted as unchanged ifosfamide. ${ }^{9}$

The antineoplastic effect of ifosfamide is exerted only by its active alkylating metabolites, ifosfamide mustard and acrolein, which result from hydroxylation of ifosfamide. Besides hydroxylation, the oxazaphosphorine ring of ifosfamide undergoes side chain dealkylation, that produces 2- and 3-dechloroethylifosfamide (non-toxic) and chloroacetaldehyde, which is the presumed causative agent of ifosfamide nephrotoxicity. ${ }^{9}$

The exact pathologic mechanisms of Ifosfamide renal damage remain unknown, but there are several pathophysiological mechanisms that can explain ifosfamide nephrotocixity: 1) binding toxic metabolites of ifosfamide to mitochondrial DNA, causing depletion of ATP; 2) 
binding to nuclear DNA, leading to blockage of cell regeneration; 3) inhibition of sodium-dependent phosphate co-transport in kidney cells by ifosfamide metabolites chloroacetaldehyde, 4-hydroperoxylifosfamide and ifosfamide mustard. ${ }^{9}$ However, further investigation is needed to confirm the exact cellular and molecular mechanisms of ifosfamide renal damage to allow the development of kidney protective protocols. Meanwhile, there is no proven strategy to minimize ifosfamide tubular toxicity. ${ }^{10,11}$

Ifosfamide nephrotoxicity may manifest with variable clinical features in different degrees of severity and incidence rates. According to literature the following manifestations have been described: 1) Glomerular toxicity (1-4\%), manifested either as acute or chronic renal failure; 2) Proximal tubular toxicity, either as complete Fanconi syndrome (1-7\% of children) or isolated defects of tubular reabsorption - aminoaciduria ( $28 \%)$; glycosuria ( $28 \%$ ), impairment of phosphate reabsorption (20-30\%), hypophosphatemia and hypophosphatemic rickets, low molecular weight proteinuria, calciuria, magnesuria and natriuria; 3) Distal tubular toxicity, presenting as subclinical impairment of urinary concentration (30\%), distal renal tubular acidosis or nephrogenic diabetes insipidus; 4) Renal toxicity - proteinuria and hypertension. ${ }^{9}$ Chronic tubular dysfunction persisting over a period of 5 years has been found in $25-47 \%$ of children treated with ifosfamide. ${ }^{10}$

All the above mentioned acid-base and hydroelectrolytic disturbances may contribute to growth failure in children ${ }^{9}$, especially chronic renal disease, hypophosphatemic rickets and renal tubular acidosis.

Renal toxicity can manifest after conclusion of ifosfamide therapy; consequently, patients should be followed up closely for a protracted period of time, even after finishing chemotherapy, ${ }^{9,12}$ especially when a higher cumulative dose was used. Carboplatin is a cisplatin analog, with a spectrum of activity similar to cisplatin, but is less nephrotoxic as it is not transformed into toxic metabolites by renal tubule cells. ${ }^{10}$ Rarely, it may cause reduction in GFR and hypomagnesemia; but the risk of renal lesion and tubulopathies is higher with combination therapy with carboplatin and ifosfamide. ${ }^{10}$

High-dose methotrexate is responsible for a decline in GFR in about $1.8 \%$ of patients. The low solubility in acid $\mathrm{pH}$ causes precipitation of the drug and metabolites within the renal tubular lumen, with subsequent obstruction, reduction of GFR and tubular cell death. Methotrexate-related nephrotoxicity appears to be entirely reversible after drug suspension, with a median time to recovery of renal function of 16 days. ${ }^{10}$

Tacrolimus produces an imbalance between vasoconstrictor factors (endothelin, thromboxane and activation of the renin-angiotensin system) and decrease of vasodilator agents (prostaglandin E2, prostacyclin, and nitric oxide), thus causing vasoconstriction of the afferent arteriole, which induces an acute reversible impairment of renal function and also acute reversible tubular dysfunction. ${ }^{8}$

As previously mentioned, our patient was medicated with several nephrotoxic drugs and sometimes more than one of these agents were used concomitantly. Nevertheless, ifosfamide is the most frequently implied in complete full Fanconi syndrome and may be irreversible. In contrast, nephrotoxicity caused by the other agents is described as reversible upon treatment terminus. $1,3,10,12$

While specific protective treatment protocols are not available, it is important to identify patients at increased risk of ifosfamide nephrotoxicity. Currently proven risk factors include higher cumulative doses (> $45 \mathrm{mg} / \mathrm{m}^{2}$ ), previous nephrectomy and concomitant administration of cisplatin or carboplatin. Younger age at treatment has been reported by some groups to be relevant; however other studies showed no independent effect and further investigation is needed. ${ }^{3,4,10,12-14}$ Remarkably, nephrotoxicity can occur even in children who do not have any of the established risk factors, which has been proposed to be due to specific pharmacogenetic differences between individuals. ${ }^{3}$

This patient was three years old when he was exposed to ifosfamide, had simultaneous treatment with carboplatin and was treated with a cumulative dose of $45 \mathrm{~g} / \mathrm{m}^{2}$ of ifosfamide. He was maintained under clinical and analytical surveillance, which at one point revealed renal damage that did not resolve after ending treatment with all nephrotoxic drugs. Upon suspicion of a tubulopathy, he was referred to the Nephrology team and diagnosed with Fanconi syndrome 1 year and 5 months after ifosfamide treatment. Upon adequate supplementation, the patient recovered appetite, wellbeing and started to show centile recovery.

Our case represents a rare situation with nonspecific clinical signs and highlights the need for close monitoring of child cancer survivors in order to identify renal toxicity and allow timely supplementation. Although some large follow-up studies have shown recovery of tubular function in some patients ${ }^{3}$ our patient maintains the need for complex supplementation 2 years after diagnosis.

In conclusion, nephrotoxicity secondary to chemotherapy is a major cause of morbidity in paediatric cancer survivors, limiting life quality and the delivery of further optimal antineoplastic treatment. Our case highlights the necessity of close monitoring of these patients to identify renal toxicity as early as possible and allow adequate supplementation. Follow up must include detailed recordings of the chemotherapy protocols administered, clinical evaluation with growth and blood pressure measurement, and, finally, laboratory surveillance of renal damage with measurement of serum creatinine, urea, electrolytes and urinalysis.

Disclosure of potential conflicts of interest: none declared.

\section{References}

1. Knijnenburg SL, Mulder RL, Schouten-Van Meeteren AY, Bökenkamp A, Blufpand H, et al. Early and late renal adverse effects after potentially nephrotoxic treatment for childhood cancer. Cochrane Database Syst Rev. 2013 Oct 8;(10):CD008944.

2. O'Sullivan D. Late effects of chemotherapeutic agents on renal function in childhood cancer survivors: a review of the literature. Ir J Med Sci. 2017 Feb;186(1):49-55.

3. Skinner R, Parry A, Price L, Cole M, Craft AW, Pearson AD. Glomerular toxicity persists 10 years after ifosfamide treatment in childhood and is not predictable by age or dose. Pediatr Blood Cancer. 2010 Jul 1;54(7):983-9.

4. Skinner R. Late renal toxicity of treatment for childhood malignancy: risk factors, long-term outcomes, and surveillance. Pediatr Nephrol. 2018 Feb;33(2):215-25.

5. Hall AM, Bass P, Unwin RJ. Drug-induced renal Fanconi syndrome. QJM. 2014 Apr;107(4):261-9, 
6. Ho PT, Zimmerman K, Wexler LH, Blaney S, Jarosinski P, Weaver-McClure L, et al. Prospective evaluation of ifosfamide-related nephrotoxicity in children and young adults. Cancer. $1995 \mathrm{Dec}$ 15;76(12):2557-64.

7. Wilmer MJ, Schoeber JP, Heuvel LP, Levtchenko EN. Cystinosis: practical tools for diagnosis and treatment. Pediatr Nephrol 2011; 26(2): 205-15.

8. Issa N, Kukla A, Ibrahim HN. Calcineurin Inhibitor nephrotoxicity: a review and perspective of the evidence. Am J Nephrol 2013;37:602-12.

9. Hartmann JT, Fels LM, Franzke A, Knop S, Renn M, Maess B, et al. Comparative study of the acute nephrotoxicity from standard dose cisplatin + -- ifosfamide and high-dose chemotherapy with carboplatin and ifosfamide. Anticancer Res. 2000; 20(5C):3767-73.

10. Nissim I, Horyn O, Daikhin Y, Nissim I, Luhovyy B, Phillips PC, et al. Ifosfamide-induced nephrotoxicity: mechanism and prevention. Cancer Res. 2006 Aug 1;66(15):7824-31.

11. Jones DP, Spunt SL, Green D, Springate JE; Children's Oncology Group. Renal late effects in patients treated for cancer in childhood: a report from the Children's Oncology Group. Pediatr Blood Cancer. 2008 Dec;51(6):724-31.

12. Loebstein R, Atanackovic $\mathrm{G}$ et al. Risk factors for long-term outcome of ifosfamide-induced nephrotoxicity in children. J Clin Pharmaco. 1999 May;39(5):454-61.
13. Randhawa PS, Starzl TE, Demetris AJ. Tacrolimus (FK506)-associated renal pathology. Adv Anat Pathol. 1997 Jul;4(4):265-76.

14. Skinner R, Cotterill SJ, Stevens MC. Risk factors for nephrotoxicity after ifosfamide treatment in children: a UKCCSG Late Effects Group study. Br J Cancer. 2000 May;82(10):1636-45.

\section{Correspondence to:}

Sónia M. Gomes, MD

Pediatric Nephrology Unit, Pediatrics Department

Hospital de Dona Estefânia, Centro Hospital Universitário de Lisboa Central, EPE Rua Jacinta Marto, 1169-045 Lisboa 